\title{
O impacto do custo de coleta do óleo residual de fritura disperso em áreas urbanas no custo total de produção de biodiesel - estudo de caso
}

\author{
Ricardo César da Silva Guabiroba ${ }^{1}$ e Márcio de Almeida D'Agosto ${ }^{2}$
}

\begin{abstract}
Resumo: O uso de biodiesel tem atraído a atenção de muitos países ao redor do mundo por ser um biocombustível renovável, além de ser menos poluente que o óleo diesel de petróleo. Apesar de ser produzido em sua grande maioria a partir de óleos vegetais virgens, o biodiesel pode ser produzido a partir de matérias-primas residuais, como a gordura animal e o óleo residual de fritura. Este último resíduo é encontrado disperso em áreas urbanas e, por essa razão, seu custo de coleta pode ser alto a ponto de tornar inviável a produção de biodiesel. A probabilidade de esse custo ser alto aumenta, quando a operação de coleta é regida de modo desorganizado e sem a existência de planejamento. É o que se observa nas operações de coleta de cooperativas populares tratadas neste estudo.

Palavras-chave: óleo residual de fritura; coleta de resíduos; roteirização; biodiesel.
\end{abstract}

Abstract: The use of biodiesel has attracted attention of many countries around the world, because it is a renewable biofuel and it is less polluting than diesel oil. Despite being made mostly from virgin vegetable oils, biodiesel can be produced from waste feedstocks, such as animal fat and waste cooking oil. This latter residue is found scattered in urban areas. Therefore, its collection costs can be as high as to make biodiesel production unfeasible. The probability of such costs being high increases when the collection operation is conducted without organization and without planning. This is what was observed in the popular cooperatives' collection operations analyzed in this study.

Keywords: waste cooking oil; waste collection; routing; biodiesel.

\section{INTRODUÇÃO}

O biodiesel é um biocombustível renovável e apresenta, como vantagem à preservação do meio ambiente, uma menor emissão líquida de dióxido de carbono em seu ciclo de vida, quando empregado como combustível em transportes, comparativamente com o óleo diesel de petróleo (D’Agosto, 2004). Além disso, o biodiesel pode ser utilizado em motores de veículos projetados exclusivamente para uso do óleo diesel de petróleo (Wassell Jr. e Dittmer, 2006), com a ressalva de que o biodiesel deve estar dentro das especificações de qualidade estabelecidas por órgãos de controle nacionais e internacionais. Por essas razões, o uso de biodiesel tem atraído a atenção de muitos países ao redor do mundo.

Na Europa e nos Estados Unidos, o biodiesel é produzido principalmente a partir de óleos vegetais provenientes da soja, da canola e do girassol. Em alguns países do sudeste da Ásia, como a Indonésia e a Malásia, essa produção é a partir do óleo de palma (Chen et al., 2009). No Brasil, os óleos vegetais virgens para a produção de biodiesel são provenientes de várias culturas, como a soja, o algodão, o girassol, a palma, o amendoim e a mamona, além das matérias-primas residuais, como a gordura animal e o óleo residual de fritura (Valente et al., 2010). De acordo com a ANP (2010), o óleo de soja representa a principal matéria-prima

\footnotetext{
${ }^{1}$ Ricardo César da Silva Guabiroba, Programa de Engenharia de Transporte, Instituto Alberto Luiz Coimbra de Pós-Graduação e Pesquisa de Engenharia, Universidade Federal do Rio de Janeiro, Rio de Janeiro, RJ, Brasil. (e-mail: ricardo_guabiroba@yahoo.com.br).

${ }^{2}$ Márcio de Almeida D'Agosto, Programa de Engenharia de Transporte, Instituto Alberto Luiz Coimbra de Pós-Graduação e Pesquisa de Engenharia Universidade Federal do Rio de Janeiro, Rio de Janeiro, RJ, Brasil. (e-mail: dagosto@pet.coppe.ufrj.br).

Manuscrito recebido em 27/9/2010 e aprovado para publicação em 31/3/2011. Este artigo é parte de TRANSPORTES v.19, n.1, 2011. ISSN:
} 2237-1346 (online). para a produção de biodiesel no Brasil $(80,95 \%$ do total). Em segundo lugar está a gordura animal $(13,88 \%)$ seguida pelo óleo de algodão $(3,57 \%)$.

De acordo com Predojevic (2008), o alto custo do biodiesel, comparado com o óleo diesel de petróleo, é o maior obstáculo a sua comercialização. Segundo Demirbas (2009), esse alto custo é dependente principalmente do custo da matéria-prima, além do custo do processo, da escala e da região de produção. $\mathrm{O}$ alto custo do óleo vegetal, principal matéria-prima para a produção de biodiesel no mundo, é fator que determina o alto custo do biodiesel (Predojevic, 2008). É possível destacar que uma grande parcela do custo final de produção do biodiesel é associada ao custo com a compra do óleo vegetal virgem (Zhang et al., 2003). Para contornar esse problema, uma opção seria a utilização de matéria-prima residual, como o óleo residual de fritura.

O óleo residual de fritura é proveniente do consumo de óleos vegetais comestíveis virgens refinados. Após esse consumo, são basicamente dois os possíveis destinos para o óleo residual de fritura: (1) esgoto sanitário, causando a poluição da água e onerando seu tratamento e (2) processadores que transformam o resíduo em um novo produto. Neste contexto, o desejável seria encaminhar esse resíduo para os processadores, como fábricas de biodiesel. Para isto, é necessário coletar o óleo residual de fritura. No entanto, esse resíduo é geralmente encontrado em uma vasta quantidade de locais, principalmente quando a área em análise é urbana. Por essa razão, é necessário verificar se o custo de coleta em área urbana torna o óleo residual de fritura mais caro que o óleo vegetal virgem para a produção de biodiesel (principal objetivo deste estudo).

É imperativo ainda definir se esse custo pode ser otimizado (um dos objetivos secundários deste estudo). Pretende-se ainda, como outros objetivos secundários, verificar a importância da utilização de um software de roteirização para a redução do custo de transporte e averiguar a melhor 


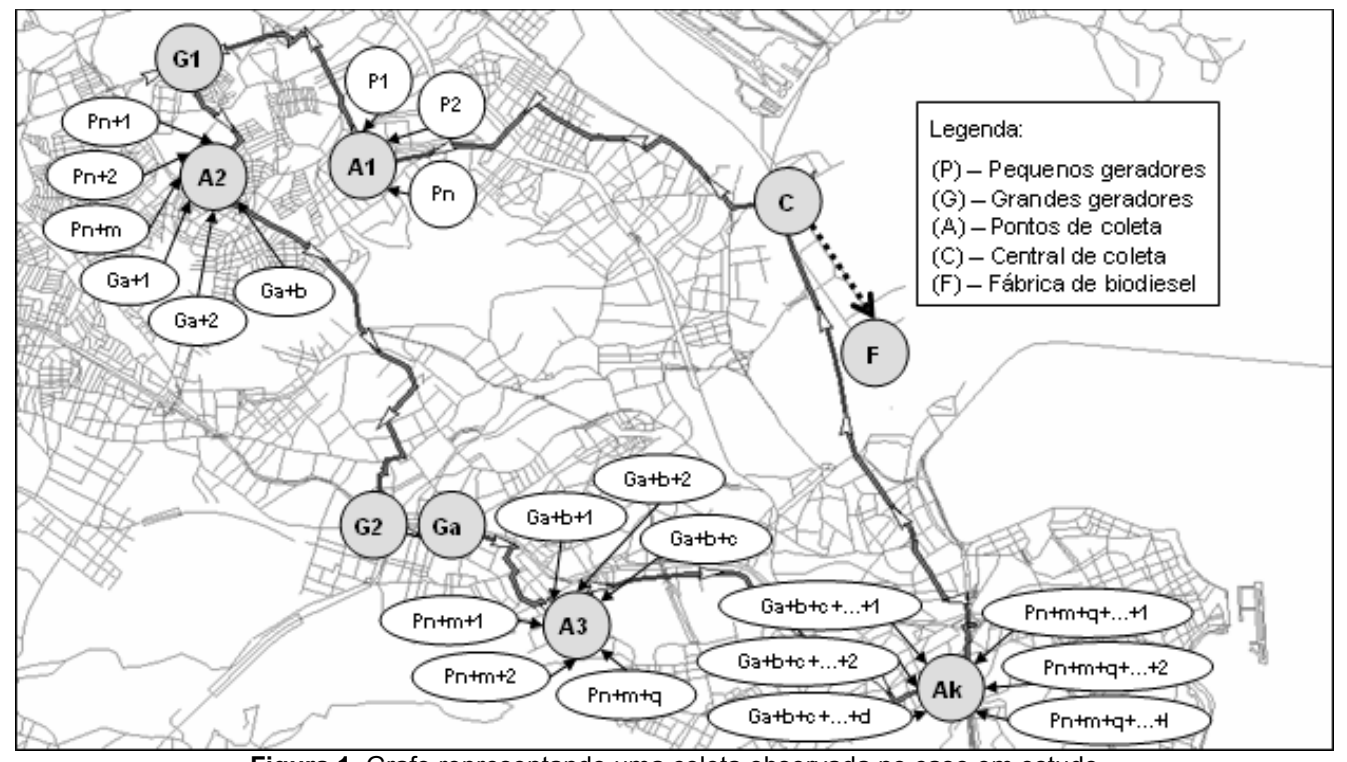

Figura 1. Grafo representando uma coleta observada no caso em estudo

opção para o produtor de biodiesel: comprar o óleo residual de fritura da cooperativa ou coletá-lo por conta própria. Neste sentido, o presente artigo apresenta, em seu item 2, a caracterização do estudo de caso de uma rede de coleta de óleo residual de fritura de modo a definir o problema a ser tratado. Em seu item 3, apresenta-se o software para a solução do problema definido no item 2. Os dados registrados em campo do caso em estudo serão apresentados no item 4 e a definição do veículo-tipo que realizou as coletas no item 5. Em seu item 6, os custos de coleta serão determinados e, em seu item 7, as discussões e conclusões sobre o estudo serão apresentadas. Por último, apresentam-se as considerações finais.

\section{CARACTERIZAÇÃO DO CASO EM ESTUDO}

O caso estudado trata-se de uma associação de cooperativas de catadores localizada na região metropolitana do Rio de Janeiro. Neste artigo, optou-se por não revelar o nome dessa associação que se encontra em um período de crescimento e de padronização de suas práticas. Neste contexto, a sede da associação de cooperativas será chamada de central Alfa de coleta.

\subsection{O problema de coleta de óleo residual de fritura}

A central Alfa, com localização conhecida, coleta o óleo residual de fritura em grandes geradores e em pontos de coleta e o fornece a uma usina de biodiesel, conforme Figura 1. O processo de coleta pode ser dividido em duas etapas: (1) planejamento e (2) operação. A etapa de planejamento tem início com o aviso enviado pelos grandes geradores e pontos de coleta sobre a existência de resíduo a ser coletado e seu volume. Essa etapa leva alguns dias, até que os pedidos de coleta sejam acumulados.

Após o acúmulo de pedidos, a etapa de operação tem início com a partida do veículo que deve visitar todos os pontos indicados para coleta apenas uma vez. Após as visitas, o motorista deve retornar para a central, onde o resíduo é tratado. A decisão sobre a sequência de coleta e o percurso entre os pontos deve ser tomada de modo a minimizar o custo total do roteiro (distância ou tempo). Além disso, o volume total coletado em cada roteiro deve ser menor ou igual que a capacidade do veículo.

O problema tratado é então definido como um Problema de Roteirização de Veículos (PRV). A estrutura de rede de pontos visitada é chamada de grafo $G=(V, E)$, onde $V=\left\{u_{0}\right.$, $\left.u_{1}, \ldots, u_{n}\right\}$ é o conjunto de vértices e $E=\left\{\left(u_{i}, u_{j}\right): u_{i}, u_{j} \in V\right\}$ é o conjunto de arcos (Tarantilis, 2005). Os fornecedores do óleo residual de fritura, no caso os grandes geradores $(G)$ e/ou os pontos de coleta $(A)$, são representados por vértices, também chamados de nós. As vias de tráfego dos veículos são representadas por arcos.

A seguir, serão apresentadas algumas características do caso em estudo, consideradas restrições que devem ser impostas ao problema de roteirização de veículos (PRV) em questão.

\subsection{Restrições observadas no caso em estudo}

As características apresentadas na Tabela 1 foram separadas de acordo com os componentes de um sistema de transportes: via, veículo, terminal e controle. As vias localizadas na região metropolitana do Rio de Janeiro, com acesso aos fornecedores, compõem as arestas de um grafo direcionado com a consideração necessária das mãos de direção. A central possui dois veículos com as mesmas características (frota homogênea) e com a disposição em horário comercial para a realização das coletas.

No caso em estudo, há apenas uma central, que pode ser considerada, como todos os doadores do resíduo, um nó do grafo. Já o controle do sistema de coleta deve considerar a troca de recipientes cheios por vazios nos doadores, a princípio sem restrição de programação. Considera-se ainda que o volume de um pedido nunca será maior que a capacidade do veículo e que cada pedido poderá ser atendido em apenas um dia. Durante a operação, mais pedidos não são incluídos (planejamento estático). Quanto à natureza, esse pedido pode ser conhecido ou facilmente previsível (determinístico). 
Tabela 1. Características do problema de coleta segundo o caso da Central Alfa

\begin{tabular}{lll}
\hline Sistema de transportes & Item de caracterização & Característica \\
\hline Via & Tipo de grafo & Direcionado \\
\hline Veículo & Características físicas & Frota homogênea (mesma capacidade) \\
& Disponibilidade de veículos & Horário comercial \\
\hline Terminal (pontos de parada) & Localização & Nós \\
& Número de centrais (P0) & Única \\
\hline Controle & Restrição de programação & Não há \\
& Pedido & Coleta e entrega simultânea \\
& Volume do pedido & Menor que a capacidade do veículo \\
& Natureza do pedido & Determinística \\
& Necessidade de atendimento & 1 dia \\
& Planejamento & Estático \\
\hline
\end{tabular}

\section{O SOFTWARE DE ROTEIRIZAÇÃO DE VEÍCULOS}

Muitas são as ferramentas computacionais capazes de solucionar o problema de roteirização de veículos (PRV). No Brasil, por exemplo, são encontrados o TruckStops Routing and Scheduling Software, o ArcLogistics Route e o TransCAD Transportation GIS em aplicações de muitas empresas. Neste estudo, o software empregado será o TransCAD, disponível no Programa de Engenharia de Transportes (PET) da COPPE/UFRJ (local onde este trabalho foi desenvolvido).

Pelizaro (2000) realizou uma comparação entre os desempenhos de dois softwares: o Delivery e o TransCAD, para solucionar os mesmos problemas teste. Foram analisados o esforço computacional para obter tais soluções, a qualidade das soluções e a robustez medida pela habilidade das heurísticas em executar bem uma grande variedade de problemas teste. Como resultado da análise, dos 51 problemas testados com características distintas, em apenas três deles o software Delivery apresentou melhor desempenho que o software TransCAD.

Outro estudo que empregou o software TransCAD como ferramenta de otimização foi o desenvolvido por Brasileiro e Aguiar (2001). Nesse trabalho, o objetivo dos autores foi efetuar a otimização do processo de coleta de resíduos provenientes do serviço de saúde oferecido na cidade de Ilha Solteira no estado de São Paulo. O processo empírico foi substituído pelo processo planejado no software TransCAD. Como resultados dessa mudança, o município atingiu uma economia de aproximadamente $22 \%$ na distância percorrida e $15 \%$ no tempo de coleta.

O fato é que o emprego dos softwares de roteirização de veículos pode trazer benefícios e isso será verificado neste artigo. Segundo Guimarães e Pacheco (2005), os softwares roteirizadores desempenham um papel importante na cadeia de suprimentos, não apenas reduzindo substancialmente os custos, mas permitindo a realização de análises que auxiliam a criação de estratégias de coleta.

\section{ROTEIRIZAÇÃO DE CINCO COLETAS REALIZADAS PELA CENTRAL ALFA}

Durante o acompanhamento de cinco coletas da central Alfa, foi possível registrar os dados relativos a todos os pontos visitados, como a localização e a demanda, além da distância percorrida para a realização das visitas. Após a cole- ta e o registro desses dados, o software TransCAD Transportation GIS foi programado para realizar a roteirização segundo uma base de vias da região metropolitana do Rio de Janeiro. Os dados obtidos por meio do TransCAD serviram como parâmetro, ao permitir a comparação com os dados coletados em campo. Assim sendo, a Tabela 2 identifica os pontos de paradas com o tipo de doador e o bairro, bem como apresenta os dados obtidos pelo TransCAD (TransCAD) e os dados coletados em campo (Campo). Considera-se que os resultados obtidos por meio do TransCAD sejam a sequência ótima de visitas e as distâncias mínimas entre os pontos de parada.

A Figura 2 apresenta outra comparação entre as distâncias coletadas em campo e as distâncias ótimas retiradas da matriz de distâncias mínimas do TransCAD. As diferenças observadas por meio dos gráficos relativos às cinco coletas acompanhadas podem ser explicadas: (1) pela inexperiência do motorista, (2) pela definição de roteiros de forma empírica e/ou (3) pela mudança do plano durante o trajeto. É possível observar essa última razão (3) no último gráfico da Figura 2. No plano, após a visita do ponto P5, o motorista deveria retornar para a central. No entanto, decidiu desviar da rota para resolver problemas pessoais e, somente após isto, voltou para o ponto de partida (P0).

Já a Figura 3 ilustra as perdas ocorridas no processo prático e que poderiam ter sido evitadas. Com os dados das distâncias registradas em campo e com os dados das distâncias mínimas obtidas por meio do TransCAD, é possível observar os potenciais de redução das distâncias percorridas. Essa redução poderia ter sido alcançada com o emprego do software TransCAD como ferramenta de roteirização.

$\mathrm{Na}$ realização de todo o roteiro da primeira coleta, por exemplo, o motorista percorreu 78,0 quilômetros. Segundo o TransCAD, essa distância poderia ter sido apenas 43,0 quilômetros (redução de quase 45\%). É possível verificar que o TransCAD reprova a sequência escolhida pelo motorista na operação empírica, ao apresentar a sequência ideal. Não apenas na primeira, mas também na quarta e na quinta operação observada, o TransCAD veio contribuir para a minimização da distância percorrida e a definição do melhor roteiro. Na segunda e na terceira operação, o TransCAD aprova a sequência estabelecida pelo motorista, contudo reprova o caminho escolhido. 
Tabela 2. Distância percorrida $(\mathrm{km})$ : dados obtidos em campo e por meio do TransCAD

\begin{tabular}{|c|c|c|c|c|c|c|c|}
\hline \multirow[b]{2}{*}{ Coleta } & \multirow[b]{2}{*}{ Paradas } & \multirow[b]{2}{*}{ Doador } & \multirow[b]{2}{*}{ Bairro (Cidade*) } & \multicolumn{2}{|l|}{ Campo } & \multicolumn{2}{|c|}{ TransCAD } \\
\hline & & & & $\operatorname{Arcos}$ & Distância & $\operatorname{Arcos}$ & Dist. \\
\hline \multirow[t]{8}{*}{1} & P0 & Central Alfa & Cidade Universitária (RJ) & $\mathrm{P} 0-\mathrm{P} 1$ & 11,0 & $\mathrm{P} 0-\mathrm{P} 1$ & 4,3 \\
\hline & $\mathrm{P} 1$ & Restaurante & Bonsucesso (RJ) & $\mathrm{P} 1-\mathrm{P} 2$ & 11,0 & $\mathrm{P} 1-\mathrm{P} 6$ & 8,5 \\
\hline & $\mathrm{P} 2$ & Cooperativa & Engenho da Rainha (RJ) & $\mathrm{P} 2-\mathrm{P} 3$ & 7,0 & P6 - P4 & 5,6 \\
\hline & P3 & Bar & Complexo do Alemão (RJ) & $\mathrm{P} 3-\mathrm{P} 4$ & 3,0 & $\mathrm{P} 4-\mathrm{P} 5$ & 7,6 \\
\hline & P4 & Condomínio & Del Castilho (RJ) & $\mathrm{P} 4-\mathrm{P} 5$ & 18,0 & $\mathrm{P} 5-\mathrm{P} 2$ & 5,6 \\
\hline & P5 & Escola & Quintino Bocaiúva (RJ) & $\mathrm{P} 5-\mathrm{P} 6$ & 20,0 & $\mathrm{P} 2-\mathrm{P} 3$ & 5,0 \\
\hline & P6 & Escola & Caju (RJ) & $\mathrm{P} 6-\mathrm{P} 0$ & 8,0 & $\mathrm{P} 3-\mathrm{P} 0$ & 6,4 \\
\hline & \multicolumn{4}{|c|}{ Distância total percorrida (quilômetros) } & $\mathbf{7 8 , 0}$ & 43,0 & \\
\hline \multirow[t]{8}{*}{2} & P0 & Central Alfa & Cidade Universitária (RJ) & $\mathrm{P} 0-\mathrm{P} 1$ & 23,0 & $\mathrm{P} 0-\mathrm{P} 1$ & 12,9 \\
\hline & $\mathrm{P} 1$ & Condomínio & Irajá (RJ) & $\mathrm{P} 1-\mathrm{P} 2$ & 11,0 & $\mathrm{P} 1-\mathrm{P} 2$ & 9,0 \\
\hline & $\mathrm{P} 2$ & Cooperativa & Engenho da Rainha (RJ) & $\mathrm{P} 2-\mathrm{P} 3$ & 11,0 & $\mathrm{P} 2-\mathrm{P} 3$ & 4,6 \\
\hline & P3 & Cooperativa & Piedade (RJ) & $\mathrm{P} 3-\mathrm{P} 4$ & 7,0 & $\mathrm{P} 3-\mathrm{P} 4$ & 6,0 \\
\hline & P4 & Casa & Engenho Novo (RJ) & $\mathrm{P} 4-\mathrm{P} 5$ & 3,0 & $\mathrm{P} 4-\mathrm{P} 5$ & 0,8 \\
\hline & P5 & Condomínio & Engenho Novo (RJ) & P5 - P6 & 9,0 & P5 - P6 & 7,8 \\
\hline & P6 & Cooperativa & Tijuca (RJ) & $\mathrm{P} 6-\mathrm{P} 0$ & 14,0 & $\mathrm{P} 6-\mathrm{P} 0$ & 13,2 \\
\hline & \multicolumn{4}{|c|}{ Distância total percorrida (quilômetros) } & 78,0 & 54,2 & \\
\hline \multirow[t]{9}{*}{3} & P0 & Central Alfa & Cidade Universitária (RJ) & $\mathrm{P} 0-\mathrm{P} 1$ & 12,0 & $\mathrm{P} 0-\mathrm{P} 1$ & 9,6 \\
\hline & $\mathrm{P} 1$ & Restaurante & Vila da Penha (RJ) & $\mathrm{P} 1-\mathrm{P} 2$ & 5,0 & $\mathrm{P} 1-\mathrm{P} 2$ & 5,0 \\
\hline & $\mathrm{P} 2$ & Condomínio & Irajá (RJ) & $\mathrm{P} 2-\mathrm{P} 3$ & 9,0 & $\mathrm{P} 2-\mathrm{P} 3$ & 4,2 \\
\hline & $\mathrm{P} 3$ & Cooperativa & Irajá (RJ) & $\mathrm{P} 3-\mathrm{P} 4$ & 11,0 & $\mathrm{P} 3-\mathrm{P} 4$ & 9,2 \\
\hline & P4 & Igreja & Piedade (RJ) & $\mathrm{P} 4-\mathrm{P} 5$ & 2,0 & $\mathrm{P} 4-\mathrm{P} 5$ & 1,7 \\
\hline & P5 & Clube & Engenho de Dentro (RJ) & P5 - P6 & 3,0 & P5 - P6 & 3,5 \\
\hline & P6 & Cozinha industrial & Engenho Novo (RJ) & $\mathrm{P} 6-\mathrm{P} 7$ & 10,0 & $\mathrm{P} 6-\mathrm{P} 7$ & 8,0 \\
\hline & $\mathrm{P7}$ & Apartamento & Rio Comprido (RJ) & $\mathrm{P} 7-\mathrm{P} 0$ & 12,0 & $\mathrm{P} 7-\mathrm{P} 0$ & 11,0 \\
\hline & \multicolumn{4}{|c|}{ Distância total percorrida (quilômetros) } & 64,0 & 52,2 & \\
\hline \multirow[t]{11}{*}{4} & P0 & Central Alfa & Cidade Universitária (RJ) & $\mathrm{P} 0-\mathrm{P} 1$ & 11,0 & $\mathrm{P} 0-\mathrm{P} 1$ & 9,1 \\
\hline & $\mathrm{P} 1$ & Cooperativa & Brás de Pina $(\mathrm{RJ})$ & $\mathrm{P} 1-\mathrm{P} 2$ & 7,0 & $\mathrm{P} 1-\mathrm{P} 2$ & 5,8 \\
\hline & $\mathrm{P} 2$ & Cooperativa & Engenho da Rainha (RJ) & $\mathrm{P} 2-\mathrm{P} 3$ & 10,0 & $\mathrm{P} 2-\mathrm{P} 3$ & 5,0 \\
\hline & P3 & Bar & Complexo do Alemão (RJ) & $\mathrm{P} 3-\mathrm{P} 4$ & 6,0 & P3 - P4 & 5,0 \\
\hline & P4 & Cooperativa & Maria da Graça $(\mathrm{RJ})$ & $\mathrm{P} 4-\mathrm{P} 5$ & 8,0 & $\mathrm{P} 4-\mathrm{P} 6$ & 5,3 \\
\hline & P5 & Condomínio & Andaraí (RJ) & $\mathrm{P} 5-\mathrm{P} 6$ & 5,0 & P6 - P5 & 2,1 \\
\hline & P6 & Vila & Vila Isabel (RJ) & $\mathrm{P} 6-\mathrm{P} 7$ & 16,0 & $\mathrm{P} 5-\mathrm{P} 7$ & 11,7 \\
\hline & $\mathrm{P} 7$ & Cozinha industrial & Botafogo (RJ) & $\mathrm{P} 7-\mathrm{P} 8$ & 2,0 & $\mathrm{P} 7-\mathrm{P} 8$ & 1,4 \\
\hline & P8 & Buffet & Botafogo (RJ) & P8 - P9 & 7,0 & P8 - P9 & 4,1 \\
\hline & P9 & Condomínio & Flamengo (RJ) & $\mathrm{P} 9-\mathrm{P} 0$ & 23,0 & $\mathrm{P} 9-\mathrm{P} 0$ & 16,1 \\
\hline & \multicolumn{4}{|c|}{ Distância total percorrida (quilômetros) } & 95,0 & 65,6 & \\
\hline \multirow[t]{7}{*}{5} & P0 & Central Alfa & Cidade Universitária (RJ) & $\mathrm{P} 0-\mathrm{P} 1$ & 19,0 & $\mathrm{P} 0-\mathrm{P} 4$ & 7,5 \\
\hline & $\mathrm{P} 1$ & Cooperativa & Tijuca (RJ) & $\mathrm{P} 1-\mathrm{P} 2$ & 13,0 & $\mathrm{P} 4-\mathrm{P} 5$ & 8,8 \\
\hline & $\mathrm{P} 2$ & Cooperativa & Piedade (RJ) & $\mathrm{P} 2-\mathrm{P} 3$ & 10,0 & $\mathrm{P} 5-\mathrm{P} 1$ & 24,6 \\
\hline & P3 & Cooperativa & Inhaúma (RJ) & $\mathrm{P} 3-\mathrm{P} 4$ & 14,0 & $\mathrm{P} 1-\mathrm{P} 2$ & 10,8 \\
\hline & P4 & Cooperativa & Penha Circular (RJ) & $\mathrm{P} 4-\mathrm{P} 5$ & 9,0 & $\mathrm{P} 2-\mathrm{P} 3$ & 6,3 \\
\hline & P5 & Cooperativa & Jardim Gramacho (DC) & $\mathrm{P} 5-\mathrm{P} 0$ & 49,0 & $\mathrm{P} 3-\mathrm{P} 0$ & 6,1 \\
\hline & \multicolumn{4}{|c|}{ Distância total percorrida (quilômetros). } & 114,0 & 64,0 & \\
\hline
\end{tabular}

\section{O VEÍCULO DE COLETA E SEUS CUSTOS OPERACIONAIS}

Para a realização das coletas, a central Alfa contou com dois veículos (furgões) fornecidos pelo governo do estado do Rio de Janeiro. Como não se possuía dados históricos operacionais desses veículos, foram utilizados dados de outro veículo (também um furgão) com características semelhantes. A Tabela 3 apresenta a composição de custos fixos e variáveis desse veículo-tipo com utilização de 2.000 quilômetros rodados por mês. O custo total para esse veículotipo é estimado em R\$2,685/quilômetro. Esse custo total mensal será utilizado no item 6 , Tabela 4, para encontrar o custo total de cada coleta a partir das distâncias registradas em campo e das distâncias obtidas por meio do TransCAD.

\section{OS CUSTOS DAS COLETAS REALIZADAS PELA CENTRAL ALFA}

A Tabela 4 apresenta as distâncias totais registradas em campo de cada uma das cinco operações de coleta. Apresenta ainda as distâncias totais mínimas obtidas por meio do software TransCAD. Com essas distâncias e com o custo de transporte total ( $\mathrm{R} \$ 2,685$ por quilômetro) obtido por meio da Tabela 3, torna-se possível a realização do cálculo 


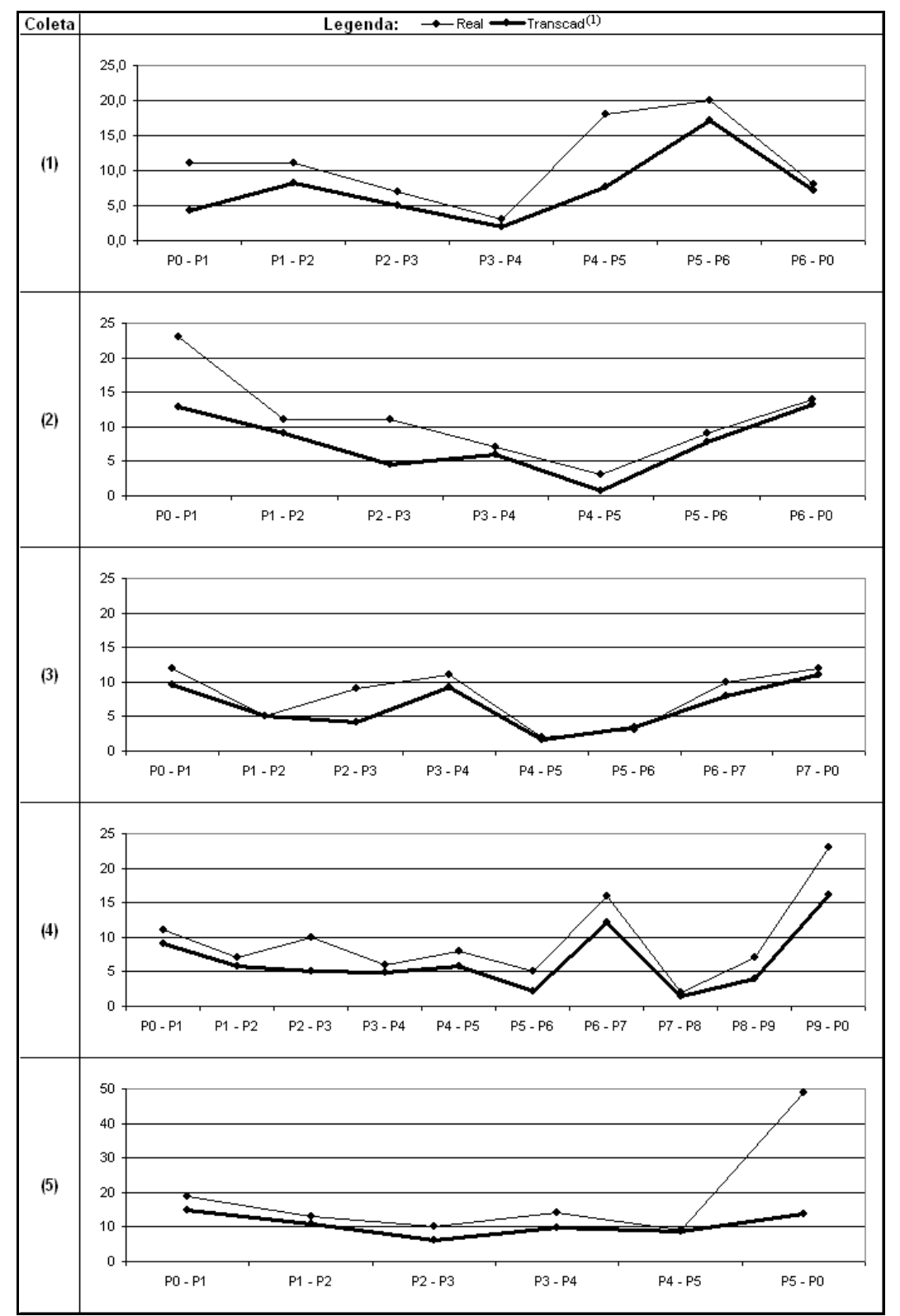

Figura 2. Distâncias coletadas em campo e as distâncias da matriz do TransCAD

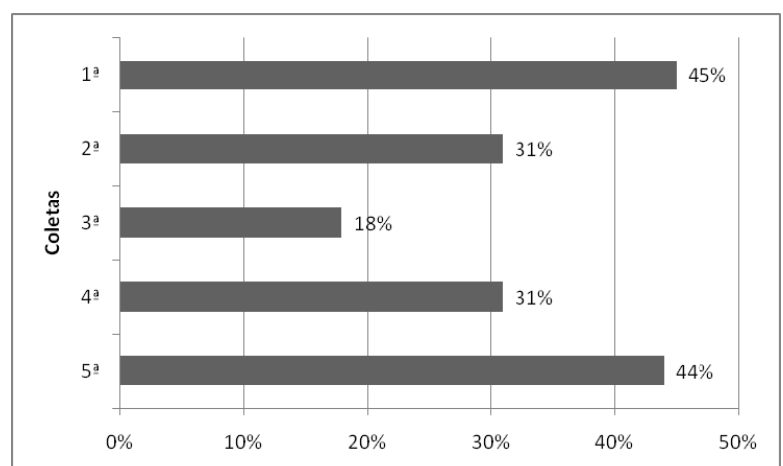

Figura 3. Potenciais perdas na operação de coleta da central Alfa

do custo de cada operação de coleta. Esse custo total (R\$) e a informação obtida em campo do volume coletado (litro) em cada operação de coleta permitem o cálculo do custo em $\mathrm{R} \$ /$ litro.

A partir desse cálculo, é possível obter a média do custo em $\mathrm{R} \$ /$ litro das cinco operações de coleta realizadas pela central Alfa. Esse custo é de R\$0,68/litro para a operação observada em campo, realizada de modo não estruturado e sem a existência de planejamento. Se o motorista conseguisse executar o roteiro conforme estabelecido pelo 
Tabela 3. Custo operacional do veículo-tipo com 2.000 quilômetros rodados

\begin{tabular}{llrr}
\hline Custo & Itens & $\boldsymbol{R} \mathbf{\$} \mathbf{k m}$ & $\boldsymbol{\%}$ \\
\hline \multirow{2}{*}{ Fixo } & Depreciação operacional & 0,2565 & 9,6 \\
& Remuneração do capital & 0,3665 & 13,7 \\
& Salário do motorista & 0,7625 & 28,4 \\
& Salário do Ajudante & 0,3813 & 14,2 \\
& Licenciamento e seguro obrigatório & 0,0815 & 3,0 \\
& Seguro facultativo & 0,1810 & 6,7 \\
& Despesas administrativas & 0,1970 & 7,3 \\
\cline { 2 - 4 } & Subtotal custos fixos & 2,2263 & 82,9 \\
\hline \multirow{2}{*}{ Variável } & Combustível & 0,2875 & 10,7 \\
& Pneus, câmaras e recapagens & 0,0397 & 1,5 \\
& Manutenção (peças e mão-de-obra) & 0,0781 & 2,9 \\
& Lubrificante do motor & 0,0128 & 0,5 \\
& Lubrificante da transmissão & 0,0006 & 0,0 \\
& Lavagem e lubrificação & 0,0400 & 1,5 \\
\cline { 2 - 4 } & Subtotal custos variáveis & 0,4587 & 17,1 \\
\hline Fusto Total & & 2,6850 & 100,0 \\
\hline Fonte: adaptado de & &
\end{tabular}

Tabela 4. Custo de cada operação de coleta realizada pela central Alfa

\begin{tabular}{|c|c|c|c|c|c|c|c|}
\hline \multirow[b]{2}{*}{ Coleta } & \multicolumn{2}{|c|}{ Distância (km) } & \multicolumn{2}{|c|}{ Custo (RS) } & \multirow{2}{*}{$\begin{array}{l}\text { Volume coletado } \\
\text { (litro) }\end{array}$} & \multicolumn{2}{|c|}{ Custo (RS/litro) } \\
\hline & Real & TransCAD & Real & TransCAD & & Real & TransCAD \\
\hline 1 & 78,0 & 43,0 & 209,43 & 115,40 & 285 & 0,73 & 0,40 \\
\hline 2 & 78,0 & 54,2 & 209,43 & 145,61 & 885 & 0,24 & 0,16 \\
\hline 3 & 64,0 & 52,2 & 171,84 & 140,08 & 190 & 0,90 & 0,74 \\
\hline 4 & 95,0 & 65,6 & 255,08 & 176,08 & 405 & 0,63 & 0,43 \\
\hline 5 & 114,0 & 64,0 & 306,09 & 171,79 & 350 & 0,87 & 0,49 \\
\hline Média & 85,8 & 55,8 & 230,37 & 149,79 & 423 & 0,68 & 0,45 \\
\hline
\end{tabular}

TransCAD, estima-se que seria menor o custo de operação e igual a $\mathrm{R} \$ 0,45 /$ litro. Considera-se ainda a existência de planejamento antes da execução do roteiro obtido por meio do TransCAD.

Em uma análise preliminar, é possível verificar que a economia obtida com o emprego do TransCAD, levando-se em conta todas as cinco rotas, seria igual a $\mathrm{R} \$ 402,91$. Considerando que o custo médio das cinco rotas programadas pelo TransCAD foi igual a $\mathrm{R} \$ 149,79$, essa economia ( $\mathrm{R} \$$ 402,91) seria capaz de pagar o custo de quase três rotas. Assim sendo, pode-se reconhecer que as perdas incorridas nas cinco coletas foram expressivas. Ressalta-se ainda o benefício de um software de roteirização para o auxílio à redução do custo de transporte.

Adicionalmente, considerando a realização de uma rota por dia, a economia por rota seria em média de $\mathrm{R} \$ 80,58$. Considerando uma média de 22 dias operacionais por mês, essa economia seria de $\mathrm{R} \$ \mathrm{R} \$ 1.772,80$. Este recurso poderia ser direcionado, em parte, para ressarcir os custos adicionais de utilização do software de roteirização e treinamento de um cooperado, se considerado uma rotina de cooperação com a universidade, como ocorre no caso em questão.

\section{ANÁLISE QUANTITATIVA E CONCLUSÕES DO ESTUDO DE CASO}

Neste item, duas análises serão realizadas. A primeira identifica o impacto da coleta do óleo residual de fritura no custo total do biodiesel para a verificação do objetivo principal deste artigo. Já a segunda análise trata de um objetivo secundário, mas importante, que aborda a escolha de um produtor de biodiesel em se comprar o óleo residual de fritura da cooperativa ou coletá-lo por conta própria.

\subsection{Impacto da coleta do óleo residual de fritura no custo total do biodiesel}

Sabe-se que grande parte do custo total do biodiesel devese ao custo da matéria-prima, quando essa matéria-prima é o óleo vegetal virgem. Segundo Haas et al. (2006), Phan (2008), Glisic et al. (2009), Sakai et al. (2009), Wen et al. (2010), Liu et al. (2010) e Kiss et al. (2010), de 70 a 95\% do custo total do biodiesel é custo com a compra do óleo vegetal virgem. De acordo com o estudo do IBP/COPPE/COPPEAD (2007), para o Brasil, 68\% do custo total do biodiesel é voltado para a aquisição do óleo vegetal virgem, $3 \%$ é relativo ao custo com o transporte em escala desse óleo e os restantes $29 \%$ são custos com a compra de insumos (álcool e catalisador), custos de produção de biodiesel (energia e mão-de-obra) e custos com impostos.

Para a produção de biodiesel a partir do óleo residual de fritura, estima-se que o custo dessa matéria-prima apresente um impacto menor no custo total do biodiesel. Segundo Guabiroba e D'Agosto (2009), estima-se que esse impacto seja em torno de $14 \%$. No entanto, é necessário verificar o custo de coleta desse resíduo. De acordo com Araujo et al. (2010), em seu estudo na cidade do Rio de Janeiro, o custo do óleo residual de fritura é de $\mathrm{R} \$ 0,46$ por litro, o custo de transporte é de R\$ 0,23 por litro e o restante dos custos R\$ 0,86 por litro. Para esse caso, o impacto do custo de coleta no custo total do biodiesel é de $15 \%$. Esse impacto pode ser considerado baixo, pois a operação de coleta, que não envolveu cooperativas populares, foi realizada de modo otimizado.

Resta agora verificar o impacto do custo de coleta da o- 


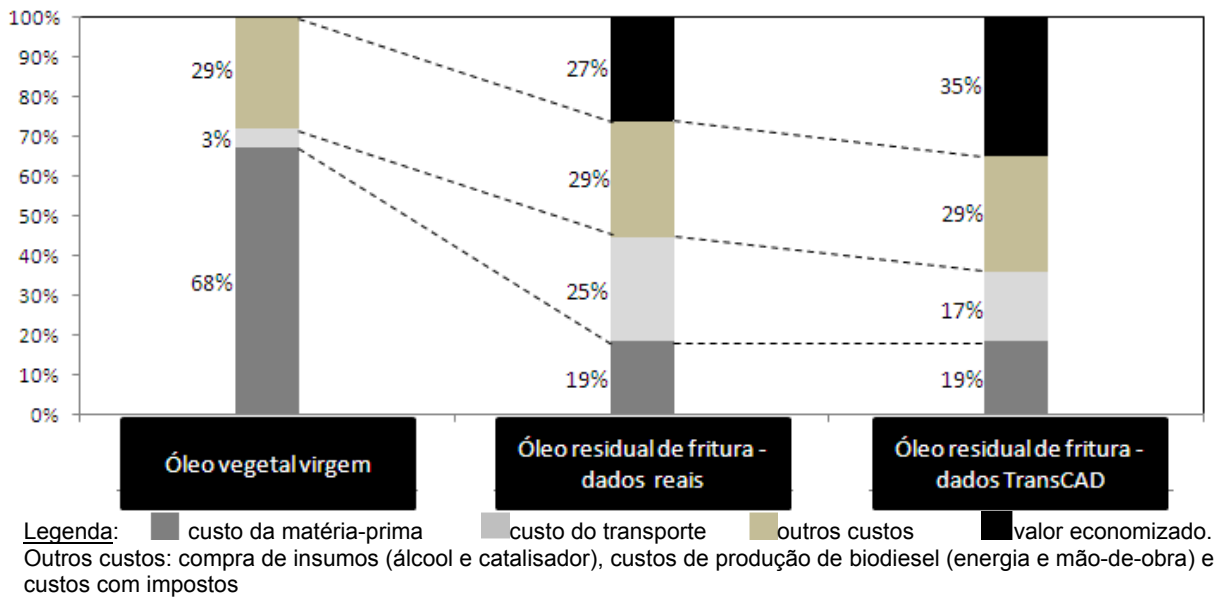

Figura 4. Distribuição percentual dos custos com a matéria-prima, transporte e outros

Tabela 5. Custo do óleo residual de fritura (R\$/litro)

\begin{tabular}{|c|c|c|c|c|}
\hline \multirow[b]{2}{*}{ Região/cidade } & \multirow{2}{*}{$\begin{array}{l}\text { Nome } \\
\text { Projeto de coleta }\end{array}$} & \multicolumn{3}{|c|}{ Custo do óleo (R\$/litro) } \\
\hline & & Mínimo & Máximo & Média \\
\hline Região Metropolitana do Rio de Janeiro (RJ) & PROVE & 0,55 & 1,00 & 0,78 \\
\hline Volta Redonda (RJ) & Eco Óleo & 0,60 & 0,60 & 0,60 \\
\hline Piracicaba (SP) & Reciclador Solidário & 0,25 & 0,40 & 0,33 \\
\hline
\end{tabular}

peração realizada pela central Alfa. Para isto, é necessário comparar o custo do óleo residual de fritura, o custo de coleta e os custos restantes de produção. O custo do óleo residual de fritura foi estimado a partir de preços desse resíduo encontrados em quatro cidades brasileiras, conforme Figura 5. A partir desses preços, é possível calcular o preço médio do óleo residual de fritura igual a $\mathrm{R} \$ 0,50$ por litro. Esse preço será considerado como o custo do óleo residual de fritura. Nota-se que é um custo próximo ao custo estabelecido por Araujo et al. (2010) e igual a R\$ 0,46 por litro. No entanto, é necessário ressaltar que esse custo varia de acordo com a localidade. No trabalho de Marchetti e Errazu (2008), por exemplo, esse custo foi estimado em R $\$ 0,92$ por litro.

Já o custo de coleta da operação realizada pela central Alfa foi calculado e apresentado na Tabela 4. O custo da coleta real foi obtido a partir dos dados coletados e registrados em campo ( $\mathrm{R} \$ 0,68$ por litro). Calculou-se ainda o custo a partir dos dados obtidos por meio do TransCAD (R\$ 0,45 por litro). Para o cálculo do impacto percentual, é necessário definir o custo total do biodiesel igual a $\mathrm{R} \$ 2,67$ por litro (incluindo o ICMS e sem a margem da distribuidora e da revenda), segundo o décimo sexto leilão da ANP ocorrido em 2009. Neste sentido, para o caso da central Alfa, o impacto do custo de coleta real ( $\mathrm{R} \$ 0,68$ por litro) no custo total do biodiesel ( $\mathrm{R} \$ 2,67$ por litro) é de $25 \%$. Se a central Alfa estivesse realizado toda sua operação conforme a roteirização do TransCAD, o impacto do custo de coleta de sua operação ( $\mathrm{R} \$ 0,45$ por litro) seria igual a $17 \%$. Já o impacto do custo do óleo residual de fritura ( $\mathrm{R} \$ 0,50$ por litro) seria de $19 \%$.

A Figura 4 permite uma melhor visualização das porcentagens correspondentes aos custos de transporte e de matéria-prima. Ao se manter constante outros custos não relacionados com a matéria-prima e com o transporte, é possí- vel visualizar o valor economizado ao se optar pelo óleo residual de fritura como matéria-prima e se optar pela realização dos processos de coleta com apoio da ferramenta de roteirização. Assim sendo, estima-se que o custo do biodiesel produzido a partir do óleo residual de fritura seria de $\mathrm{R} \$$ 1,95 por litro, com esse resíduo coletado de modo empírico pela central Alfa. Se a operação de coleta estivesse em acordo com a roteirização do TransCAD, o custo do biodiesel seria ainda menor ( $\mathrm{R} \$ 1,72$ por litro).

Neste estudo de caso, é imperativo reconhecer que o custo da coleta realizada pela central Alfa mais o custo do óleo residual de fritura (total 44\%) têm um impacto bem menor no custo total do biodiesel comparativamente com o custo do óleo vegetal virgem mais seu custo de transporte (total $71 \%$ ). A economia obtida em se optar pelo óleo residual de fritura chega a $27 \%$ (equivalente a $\mathrm{R} \$ 0,72$ por litro). É possível verificar ainda que as coletas, realizadas de modo empírico, podem ser aprimoradas com o apoio da técnica de roteirização. Neste estudo, o custo da coleta realizada pela central Alfa, igual a $25 \%$ do custo total do biodiesel (vide Figura 4), pode ser reduzido para 17\% (impacto próximo ao impacto de $15 \%$ verificado no trabalho de Araujo et al. (2010), em que a operação era otimizada). Com o custo de coleta reduzido, a economia obtida em se optar pelo óleo residual de fritura chega a ser de $35 \%$ ou $\mathrm{R} \$ 0,95$ por litro. Este fato remete à importância de um software de roteirização para a otimização do processo de coleta que permite a redução do custo logístico.

\subsection{Melhor opção para o produtor de biodiesel}

Após a observação da prática, é possível definir duas opções para a fábrica de biodiesel: (1) comprar e coletar o óleo residual de fritura ou apenas (2) comprar o óleo com o frete incluído. $\mathrm{O}$ preço máximo do resíduo encontrado foi o de $\mathrm{R} \$ 1,00$ por litro, conforme Tabela 5. Esse preço é o re- 
lativo à opção (2), isto é, a fábrica de biodiesel paga $\mathrm{R} \$$ 1,00 pelo litro do resíduo e o recebe em sua planta de produção.

Considerando-se o preço de mercado de $\mathrm{R} \$ 1,00$ por litro como referência para a opção (2), é possível comparar com o custo para a obtenção do óleo residual de fritura na opção (1). Esse custo de obtenção é composto pelo custo da matéria-prima mais o custo com a coleta. $\mathrm{O}$ custo de coleta foi calculado no item 6 e apresentado na Tabela 4. Esse valor é R\$ 0,68 por litro para a coleta real (dados coletados em campo) e R\$ 0,45 por litro para a coleta sugerida pelo TransCAD (otimizado e 34\% menor). Já o custo com a matéria-prima pode ser considerado nulo, pois o resíduo foi doado em todos os pontos visitados.

Analisando-se as duas opções do ponto de vista da fábrica de biodiesel, pode-se concluir que a opção (1) é a mais vantajosa. Ao analisar cada cidade mencionada na Tabela 5 em separado, é possível obter outras conclusões. No Rio de Janeiro, a fábrica de biodiesel terá como melhor opção coletar o óleo. No entanto, se o preço de mercado cair para o mínimo já registrado igual a $\mathrm{R} \$ 0,55$ por litro, somente se o processo de coleta estiver sendo executado de forma ótima (custo otimizado da coleta igual a $\mathrm{R} \$ 0,45$ por litro) a fábrica estará levando vantagem.

Em Porto Alegre, a melhor opção é comprar o óleo com o frete incluído, principalmente se o preço for o mínimo e igual a R\$ 0,10 por litro. Já em Volta Redonda, o preço de mercado é R\$ 0,60 por litro. Se a fábrica de biodiesel que possui doadores do resíduo conseguir otimizar sua coleta, de modo que seu custo seja por volta de R \$ 0,45 por litro, é mais vantajoso coletar o óleo para o seu próprio suprimento. Em Piracicaba, o preço de mercado é baixo com valor máximo de R\$ 0,40 por litro. Assim sendo, a melhor opção seria comprar o resíduo com o frete incluído.

\section{CONSIDERAÇÕES FINAIS}

O objetivo principal deste artigo foi alcançado ao se constatar que o óleo residual de fritura, principalmente quando coletado de modo otimizado e planejado, pode ser mais barato para a produção de biodiesel que o óleo vegetal virgem. Outros três objetivos secundários foram alcançados: (1) após a observação das práticas da central Alfa, foi possível constatar que o custo total das cinco coletas poderia ter sido 34\% menor, se otimizado; (2) um software de roteirização auxiliaria no processo de redução do custo logístico e (3) o mais barato para o produtor de biodiesel, que encontre o óleo residual de fritura a R\$ 1,00 por litro no mercado, seria coletar o resíduo, principalmente se este é doado.

Ficou ainda constatado que apenas a otimização do processo de coleta não garante o sucesso da operação. Assim sendo, todo o processo administrativo e logístico deve estar estruturado. É necessário que se entenda o processo de coleta não apenas como a elaboração de uma rota que minimize seu custo total, mas sim como um processo de gestão que envolve seu planejamento e sua operação em que a roteirização é uma de suas atividades. Neste sentido, os procedimentos devem estar estruturados, as atividades devem estar padronizadas e os colaboradores devem estar treinados para que as práticas de coleta sejam realizadas de forma adequada, a fim de garantir uma uniformidade na oferta de óleo residual de fritura, mesmo não conseguindo atender toda a demanda de uma fábrica de biodiesel.
No entanto, a estruturação de cooperativas populares não é um processo fácil e geralmente não possuem potencial de investimento. A compra de um software, como o TransCAD, e seu manuseio é algo inviável para essas cooperativas. A compra de veículos novos e de baixo custo operacional também é algo impraticável para a grande maioria dessas cooperativas. No caso estudado, a intervenção da universidade (Programa de Engenharia de Transportes da COPPE/UFRJ) para o fornecimento gratuito do software e a intervenção do governo estadual para o fornecimento dos veículos foram primordiais para a melhoria dos processos da central Alfa. No entanto, mesmo com esse auxílio, observou-se que as práticas de coleta observadas em campo apresentaram um custo potencialmente elevado (R\$ 0,68 por litro). Ressalta-se ainda que esse custo não incluiu o custo com o tempo e o trabalho do cooperado exercendo a função de analista, pois este não é remunerado, conforme regime comum em cooperativas.

Mesmo com a utilização de um software roteirizador para a otimização dos processos de coleta, ainda há a possibilidade desse plano não ser executado na prática. Muitas são as situações que o motorista pode encontrar durante o trajeto em área urbana, como tráfego intenso e acidentes, além de replanejamentos que acontecem no decorrer da operação. Embora não se tenha acompanhado nenhuma situação de tráfego intenso nem de acidentes durante o registro de dados em campo, dependendo da localização dos pontos de coleta e grandes geradores, é certamente possível que o motorista venha a enfrentar este tipo de situação. Quanto à implementação de um sistema de replanejamento ou programação dinâmica, o uso de acompanhamento em tempo real da operação dos veículos por meio de sistema de GPS e/ou rádio (tipo $\operatorname{Nextel}^{\circledR}$ ) poderiam auxiliar na redução do custo operacional de coleta a custas de um investimento adicional que também pode não ser do alcance das cooperativas. Ainda assim, acredita-se que isto só será viável a partir da melhoria do fluxo de informações. Caso contrário, o processo de coleta cairá novamente no empirismo fortemente dependente da experiência do motorista.

\section{REFERÊNCIAS BIBLIOGRÁFICAS}

ANP (2010) Boletim mensal do biodiesel. Agência Nacional do Petróleo, Gás Natural e Biocombustíveis. Disponível em: <http://www.anp. gov.br/>.

Araújo, V. K. W. S.; S. Hamacher e L. F. Scavarda (2010) Economic assessment of biodiesel production from waste frying oils. Bioresource Technology, v. 101, p. 4415-4422.

Brasileiro, L. A. e J. Aguiar (2001) Uma análise sobre a utilização de SIG$T$ no roteamento de veículos de coleta de residuos de serviços de saúde. Faculdade de Engenharia de Ilha Solteira (FEIS/UNESP), SP, Brasil.

Chen, Y.; B. Xiao; J. Chang; Y. Fu; P. Lu e X. Wang (2009) Synthesis of biodiesel from waste cooking oil using immobilized lipase in fixed bed reactor. Energy Conversion and Management, v. 50, p. 668673.

D’Agosto, M. A. (2004) Análise da eficiência da cadeia energética para as principais fontes de energia utilizadas em veículos rodoviários no Brasil. Tese (doutorado), COPPE/UFRJ, Engenharia de Transportes, Rio de Janeiro, Brasil.

Demirbas, A. (2009) Biodiesel from waste cooking oil via base-catalytic and supercritical methanol transesterification. Energy Conversion and Management, v. 50, p. 923-927.

Glisic, S.; I. Lukic e D. Skala (2009) Biodiesel synthesis at high pressure and temperature: Analysis of energy consumption on industrial scale. Bioresource Technology, v. 100, p. 6347-6354.

Guabiroba, R. C. e M. A. D'Agosto (2009) O processo de roteirização como elemento de redução do custo de coleta de óleo residual de fri- 
tura em área urbana para a produção de biodiesel. Dissertação (mestrado), COPPE/UFRJ, Engenharia de Transportes, Rio de Janeiro, Brasil.

Guimarães, G. S. e R. F. Pacheco (2005) Análise da viabilidade do uso de um software de roteirização de veículos em uma empresa agroindustrial. Anais da XXV ENEGEP, Porto Alegre, RS, Brasil.

Haas, M. J.; A. J. McAloon; W. C. Yee e T. A. Foglia (2006) A process model to estimate biodiesel production costs. Bioresource Technology, v. 97, p. 671-678.

IBP/COPPE/COPPEAD (2007) Aspectos técnicos e logísticos para a produção de biodiesel no Brasil. Instituto Brasileiro de Petróleo, Gás Natural e Biocombustíveis Rio de Janeiro, Brasil.

Kiss, F. E.; M. Jovanović e G. C. Bošković (2010) Economic and ecological aspects of biodiesel production over homogeneous and heterogeneous catalysts. Fuel Processing Technology, v. 91, p. 13161320 .

Liu, S.; T. McDonald e Y. Wang (2010) Producing biodiesel from high free fatty acids waste cooking oil assisted by radio frequency heating. Fuel, v. 89 , p. $2735-2740$.

Marchetti, J. M. e A. F. Errazu (2008) Technoeconomic study of supercritical biodiesel production plant. Energy Conversion and Management, v. 49, p. 2160-2164.

Pelizaro, C. (2000) Avaliação de desempenho do algoritmo de um programa comercial para roteirização de veículos. Dissertação (mestrado), Escola de Engenharia de São Carlos, Universidade de São Paulo, São Carlos, SP, Brasil.

Phan, A. N. e T. M. Phan (2008) Biodiesel production from waste cooking oils. Fuel, v. 87 , p. $3490-3496$.

PP (2008) Óleo de fritura. Prefeitura de Piracicaba. Disponível em: $<$ http://www.piracicaba.sp.gov.br/>

PPA (2007) Projeto: destinação de óleo de fritura - divulgação. Prefeitura de Porto Alegre.

Predojevic, Z. J. (2008) The production of biodiesel from waste frying oils: A comparison of different purification steps. Fuel, v. 87, p. 3522-3528.

PROVE (2007) Estruturação e modelagem funcional. Programa de Reaproveitamento de Óleos Vegetais do Estado do Rio de Janeiro, Rio de Janeiro, Brasil.

PVR (2008) Informações a respeito do projeto de coleta de óleo residual na cidade de Volta Redonda. Comunicação pessoal, Banco da Cidadania, Prefeitura de Volta Redonda, Volta Redonda, RJ.

Sakai, T.; A. Kawashima e T. Koshikawa (2009) Economic assessment of batch biodiesel production processes using homogeneous and heterogeneous alkali catalysts. Bioresource Technology, v. 100, p. 3268-3276.

Tarantilis, C. D. (2005) Solving the vehicle routing problem with adaptive memory programming methodology. Computers \& Operations Research, v. 32, p. 2309-2327.

Transporte Moderno (2008) Custos operacionais. OTM editora, ano 45, n. 431.

Valente, O. S.; V. M. D. Pasa; C. R. P. Belchior e J. R. Sodré (2010) Physical-chemical properties of waste cooking oil biodiesel and castor oil biodiesel blends. Fuel, v. 90, n. 4, p. 1700-1702.

Wassell Jr., C. S. e T. P. Dittmer (2006) Are subsidies for biodiesel economically efficient? Energy Policy, v. 34, p. 3993-4001.

Wen, Z.; X. Yu; S. Tu; J. Yan e E. Dahlquist (2010) Biodiesel production from waste cooking oil catalyzed by $\mathrm{TiO}_{2}-\mathrm{MgO}$ mixed oxides. Bioresource Technology, v. 101, p. 9570-9576.

Zhang Y.; M. A. Dubé; D. D. Mclean e M. Kates (2003) Biodiesel production from waste cooking oil: 2 . economic assessment and sensitivity analysis. Bioresource Technology, v. 90, p. 229-240. 